\title{
Shifted indexicals in Hong Kong Sign Language with(-out) role shift
}

\author{
Linghui Eva Gan (University of Connecticut) \\ ganlinghui@gmail.com
}

\begin{abstract}
This study investigates shifted indexicals in Hong Kong Sign Language (hereafter HKSL). In elicited data, shifted indexicals are attested in utterances with and without attitude role shift. The data further show that attitude role shift has both quotation-like and nonquotation-like characteristics, leading to the conclusion that neither of the two major accounts for role shift, the Demonstration Account by Davidson (2015) or the Indexical Shifting Operator Account by Schlenker (2017b, 2017a) suffices to fully explain role shift. Moreover, the interpretations of the indexicals seem to depend on the exact form of the embedding predicate. Crucially, a shifted interpretation is available only under what I notate as VERB-2 but not VERB-3. I propose that VERB-2 can act as neutral agreement that leads to ambiguous interpretations of the sentences.
\end{abstract}

Keywords: indexical shift, role shift, quotation, agreement marking, HKSL

\section{Shifted indexicals in spoken languages}

Indexicals are context-dependent expressions (Kaplan 1989), which include pronouns, such as $I$, you; locative indexicals such as here; and temporal indexicals such as today, now, tomorrow, etc. In many languages, indexicals in indirect reports are typically interpreted based on the context in which the entire sentence is uttered, such as English (1).

(1) John said that I am rich.

$(I=$ speaker; $\neq$ John $)$

In some languages, however, indexicals can depend on the context of the reported speech act (i.e., indirect speech), dubbed as indexical shift. In languages that allow indexical shift, sentences with the form John said that I am rich can report John's self-ascription of being rich, instead of the speaker. Examples of such languages are Amharic (2)(Schlenker 2003), Zazaki (Anand and Nevins 2004), Korean (Park 2014), etc. The shifting patterns differ across languages. For instance, in Amharic, only the first and second personal indexicals can shift (optionally). In Zazaki, all indexicals can shift, and shifting is optional for pronominal and locative indexicals but obligatory for temporal indexicals (for a typological summary, see Schlenker 2011 and Deal 2020). It has been argued that these languages have an operator that is responsible for the shifting of indexicals.

(2) [Amharic, Schlenker 2003, ex. 53]

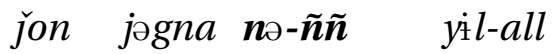

John hero be.PF-1sO 3M.say-AUX.3M

'John says that he is a hero.' 
Another linguistic context in which indexicals are interpreted relative to a reported context rather than to the actual utterance context is quotations (i.e., direct speech), as shown in the English example (3).

(3) John said: "I was born here." ( $I=$ John, $\neq$ speaker; here $=$ the location where John was)

For simplicity, in this study, I will refer to any indexical anchored to the reported rather than the actual utterance context as a shifted indexical. This is independent from whether it occurs in indirect speech (i.e., shifted indexical in the strict sense), or in a quotation.

\section{Role shift in sign languages}

Role shift in sign languages signals that the signer assumes the role of another character and conveys information from that character's perspective. It commonly involves a change in facial expressions, eye gaze, and possibly also head position change and body lean (Cormier, Smith, and Sevcikova-Sehyr 2015; Lillo-Martin 2012). In this study, I will adopt Schlenker's (2017) categorizations of two types of role shift. Role shift in which the signer reenacts actions of the reported individual is called action role shift. The reenaction usually starts after the subject has been introduced (e.g., IX-3 BIRD 'that bird' in Figure 1a). Role shift in which the signer represents the thoughts or utterances of another is called attitude role shift. The representation is often introduced by an attitude verb such as SAY and THINK (Figure 1b).

Figure 1: Examples of action role shift (a) and attitude role shift (b)

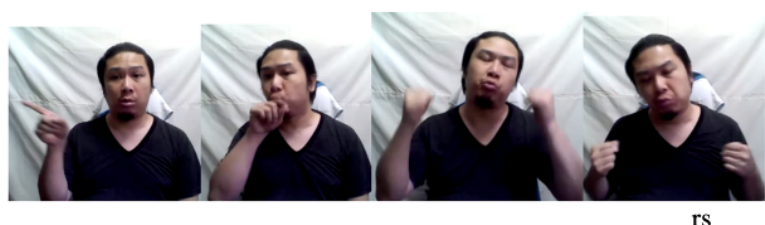

(a) IX-3 BIRD $\overline{\text { CA (playing-on-the-swing) }}$ 'The bird was like this (playing on the swing.)'

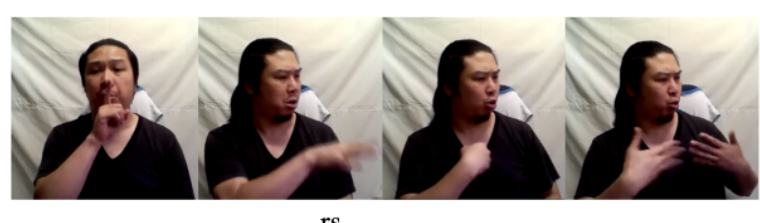

(b) MOM SAY-3 IX-1 BUSY 'Mom said: "I am busy."

Shifted indexicals under role shift are attested in various sign languages (Hübl, Maier, and Steinbach 2019; Hübl 2012; Quer 2016, 2013; Zucchi 2004; Quer 2011), and have been accounted for in two different ways. The first one I will refer to as the 'Demonstration Account': Davidson (2015) adopts event semantics and argues that role shift is a form of demonstration. There are two subtypes: action role shift is a body classifier construction (Supalla 1986), and attitude role shift is a quotation. This account predicts that attitude role shift should pattern with quotations in spoken languages in anchoring all indexicals with respect to the reported rather than the actual utterance context (3), and in banning wh-extractions (4). In addition, the quoted material in a quotation is independent from the matrix clause, as indicated by the different interpretations of the pronoun he (5): in indirect speech but not a quotation, he can be bound by the matrix subject every student.

(4) (a) *What did Aaron say "I understand _"?

(b) Aaron said: "I understand ASL."

(5) (a) Every student said: "He ${ }_{\mathrm{j}} / \mathrm{k}$ likes Hong Kong Sign Language."

(b) Every student $t_{j}$ said that he $\mathrm{j}_{\mathrm{j} / \mathrm{k}}$ likes Hong Kong Sign Language. 
Alternatively, Schlenker (2017a, 2017b), following in the spirit of previous proposals, argues that role shift is a context-shifting operator, parallel to the indexical shifting operators in spoken languages. ${ }^{1}$ This account is referred to as the 'Indexical Shifting Operator Account' here. It is parameterized to account for cross-linguistic variations: in American Sign Language (ASL) and French Sign Language (LSF) (6), indexicals necessarily shift; in Catalan Sign Language (LSC) and German Sign Language (DGS) (7), however, mixed-shifting of the indexicals is possible. In (7), the pronoun IX-1 is shifted to the reported context, whereas TOMORROW anchors to the context of the utterance.

(6) Context: In 2010, I met Jean in LA. At the time, he often changed jobs and home bases. DATE 2010 PLACE LA JEAN SAY IX-1 YEAR NOW WORK PARIS.

'In 2010, in LA, Jean said: 'This year (2010) I (Jean) work in Paris.'

[LSF, Schlenker 2017a]

(7) YESTERDAY PETER IX-3 SAY TOMORROW IX-1 ARRIVE.

'Yesterday Peter said that he will arrive tomorrow.'

[DGS, Herrmann and Steinbach 2012]

In this study, I evaluate the above two accounts by examining HKSL data. I ask two research questions: RQ1: Do indexicals under role shift necessarily shift? RQ2: Can shifted indexicals occur without role shift?

\section{Methodology}

The data were elicited remotely via Zoom from two deaf HKSL signers whose parents are both deaf (male, 30s \& 40s). The data collection included several sessions during November 2020, and was recorded with the consultants' consent. The communication language was HKSL. There were two steps. The first step was a translation task. One signer was asked to translate written sentences (in Chinese) into HKSL. The indexicals included in the stimuli sentences were: IX-1, WE-TWO, HERE, TOMORROW, and TODAY. The three matrix verbs considered were SAY 'say/tell' (agreeing verb); THINK and GUESS (both are body anchored plain verbs, Padden 1988). The sentences were signed in two conditions: without role shift (i.e., indirect report), and with role shift (i.e., attitude role shift). ${ }^{2}$ In the second step, both consultants were separately asked to watch the played-back videos collected in Step 1 and give acceptability judgements. First, they were asked to judge the grammaticality of the sentences (three point scale: good; so-so; bad). Sentences judged as 'bad' were excluded in the further analysis. They then judged the interpretation of the indexicals (whether or not they can get a shifted interpretation). To obtain some background information, I also asked the signers why the sentences were unacceptable to them. ${ }^{3}$

1. Before Schlenker, Zucchi (2004) proposes that role shift is a signer shifting operator. It assigns the value of the shifted perspectival center to first person pronouns under role shift, so that they can refer to individuals other than the signer. However, he does not consider indexicals other than first person.

2. The instruction for the two conditions was signed as: ROLE-SHIFT NOT-HAVE/HAVE .

3. During the data collection, supplementary sentences were also consulted, which derived from modifications of the starting point of the role shift or involving different matrix verbs. For ease of communication, these sentences were presented in the form of English glossing of the signing. Note that both consultants had linguistic training and are familiar with the glossing conventions, and they had no problem understanding the sentences and reproducing the signing accordingly. 


\section{Data: shifted indexicals in HKSL}

Without role shift, the signing is articulated in the neutral direction (straight facing); with (attitude) role shift, the signing is accompanied by a perceptible body shift from straight facing to one side and an optional backward/forward body lean. The eye gaze also shifts direction sidewards, away from the addressee in the utterance context (i.e., the author, on the screen). Table 1 summarizes the judgements by the two consultants. Under role shift, all indexicals must shift. Interestingly, despite certain variations between the two signers (to be described below), without role shift, some indexicals also shift: IX-1 'I', WE-TWO, and HERE optionally shift, TOMORROW obligatorily shifts. ${ }^{4}$

Table 1: Judgements on shifted indexicals by the two consultants

\begin{tabular}{llll} 
Indexicals & \multicolumn{2}{l}{ a) without role shift } & b) with role shift \\
& Signer A (S.A.) & Signer B (S.B.) & \\
\hline IX-1 & optional & optional & obligatory \\
WE-TWo & optional & none & obligatory \\
HERE & optional & optional & obligatory \\
TOMORROW & obligatory & obligatory & obligatory \\
TODAY & obligatory & none & obligatory \\
\hline
\end{tabular}

Figure 2: Demonstration of the signing directions indicated by the notation on verbs

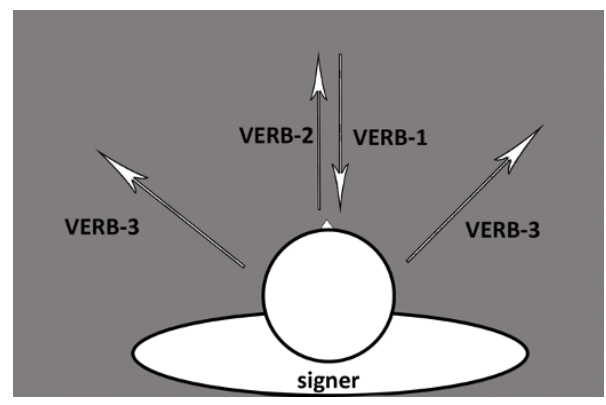

Before moving to the details of the data, it is necessary to introduce the notation convention. In the HKSL data to be listed, the number following the agreeing verbs (Padden 1988; Cormier, Wechsler, and Meier 1998) indicates the signing direction of the signs along the transverse plane of the signer, as illustrated in Figure 2. VERB-1: the verb is articulated towards the signer. (The grey area in Figure 2 covers possible starting points); VERB-2: the verb is articulated towards a vertical direction away from the signer (indicated by the arrow only); VERB-3: the verb is articulated towards a non-vertical direction away from the signer (usually a diagonal direction as the arrows indicate, but the grey area covers possible end points). ${ }^{5}$ This notation convention departs from the more standard assumption in the literature that the differences in morphology realize verbal agreement (see Mathur and Rathmann (2012) for a summary of different approaches). For instance, TELL-1 'tell me', TELL-2 'tell you', and

4. Kimmelman and Khristoforova (2018) also found that indexicals without role shift can be shifted in RSL. However, the opposite pattern is also attested, i.e., indexicals with role shift can be non-shifted, which is not possible in HKSL.

5. For VERB-2 and VERB-3, the onset location is assumed to be identical or close to the citation form of the verbs, e.g., for SAY, it starts at the location in front of the signer's mouth. 
TELL-3 'tell him/her/them.SG'. However, in this paper, this connection is not assumed, as I will argue later, verb-2 does not exclusively denote second person agreement. It can also be a neutral direction that does not mark agreement. Moreover, for agreeing attitude predicates, VERB- 2 can cause an ambiguity between a pure indirect sentence and a quotation.

With role shift, the first singular person pronoun IX- 1 always shifts ( $8 \mathrm{a})$; without role shift, it is ambiguous ( $8 \mathrm{~b})$. According to the signers, in an indirect report, the sign SELF (body-anchored) is preferred over IX-1 to refer to the reported individual (9a). With role shift, the sentence is also acceptable $(9 \mathrm{~b})$, and it refers to the reported individual as well. I will come back to discuss SELF in the later sections.
(a) $\operatorname{MOM}_{i} \overline{\mathrm{SAY}-3 \mathrm{IX}-\mathbf{1}_{i / * j} \mathrm{BUSY}}$
'Mom said that \{she is, \#I am\} busy.'
(b) MOM $_{i}$ SAY-2 IX-1 $\mathbf{1}_{i / j}$ BUSY
'Mom said that $\{\mathrm{I}$ am, she is $\}$ busy.'

(a) $\operatorname{MOM}_{i} \mathrm{SAY}^{2} \mathrm{SELF}_{i / * j} \mathrm{BUSY}$

'Mom said that $\{$ she is, \#I am\} busy.'

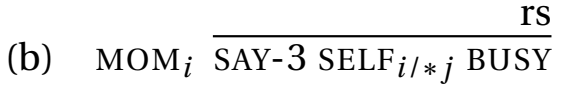

'Mom said that \{she is, \#I am\} busy.'

With role shift, the pronoun WE-TWO only gets a shifted interpretation (10 a) ${ }^{6}$ Without role shift, however, for Signer A (S.A.), it can mean either the signer and the addressee (i.e., a non-shifted interpretation), or Connie and her addressee (i.e., both indexicals shift), but Signer B (S.B.) only gets the non-shifted reading (10 b).
(a) CONNIE $_{i} \frac{\text { SAY-3 WE-TWO }}{i+2 / * j+2 \text { FRIEND }}$
'Connie said that $\{$ Connie \& her addressee, \#signer \& their addressee $\}$ are friends.'
(b) CONNIE $_{i}$ SAY- 2 WE-TWO $\% i+2 / j+2$ FRIEND
'Connie said that $\{\%$ Connie $\&$ her addressee, signer $\&$ their addressee $\}$ are friends.'
(Note: \% means controversial judgements between the two signers. S.A.: can shift; S.B.: not shift)

The locative indexical HERE always shifts with role shift (11 a); without role shift, it is ambiguous (11 b).

(11) Context: Aaron and Kenny are having the conversation in Hong Kong. Aaron said:

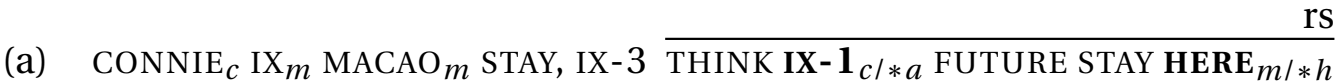 'When Connie was in Macao, she thought that $\{$ she, \# I $\}$ will stay in $\{$ Macao, \#Hong Kong\}.'
(b) CONNIE $_{c}$ IX $_{m}$ MACAO $_{m}$ STAY, IX-3 THINK IX-1 I $_{a}$ FUTURE STAY HERE $m / h$ 'When Connie was in Macao, she thought that \{she will stay in Macao, I will stay in Hong Kong\}.'

6. Form of the sign WE-TWO: a K-handshape moving back and forth between the signer and the other person in 'we two'. 
In terms of temporal indexicals, with role shift, TODAY necessarily shifts (12a). Without role shift, the two signers have different judgements. For Signer A, TODAY always shifts; for Signer B, it does not shift, i.e., it can only mean the date on which the sentence was uttered (12 b). Interestingly, with and without role shift, TOMORROW necessarily gets the shifted interpretation. It always refers to the reported context (13).

(12) Utterance time: the day of the data collection $(2020 / 11 / 12)$.

YEAR 2020 OCTOBER-FIRST,
(a) CONNIE GUESS TODAY LISA COME
'On October 1st 2020, Connie guessed that Lisa would come on $\{2020 / 10 / 01$, \#2020/11/12\}.'
(b) CONNIE GUESS TODAY LISA COME
'On October 1st 2020, Connie guessed that Lisa would come on:
S.A.: $\{2020 / 10 / 01, \# 2020 / 11 / 12\} ;$ S.B.: $\{\# 2020 / 10 / 01,2020 / 11 / 12\}$.'

(13) Utterance time: the day of the data collection (2020/11/12).

YEAR 2020 OCTOBER-FIRST,
(a) CONNIE GUESS TOMORROW LISA COME
'On October 1st 2020, Connie guessed that Lisa would come on $\{2020 / 10 / 02$, \#2020/11/13\}.'
(b) CONNIE GUESS TOMORROW LISA COME
'On October 1st 2020, Connie guessed that Lisa would come on $\{2020 / 10 / 02$, \#2020/11/13\}.'

Readers would have noticed that the scope of attitude role shift consistently starts from the matrix verbs, which is different from ASL (c.f., Koulidobrova and Davidson $(2015,2020)$ and (18)). In addition, in the examples with agreeing verbs, the morphological marking of the verb is VERB-3 in sentences with role shift, and VERB-2 in sentences without role shift. According to the consultants, both VERB- 3 and VERB- 2 are acceptable for sentences without role shift, but with role shift, only VERB-3 is acceptable (Figure 3).

This is not surprising, as role shift in HKSL contains a sideward body shift, and it also starts on the matrix verb, yielding a verb with a 'shifted direction' (SAY-3). It is not yet clear, however, why attitude role shift has to start from the matrix verbs.

\section{Role shift: quotation-like and non-quotation-like}

In the HKSL data presented above, both non-quotation-like and quotation-like characteristics are attested for attitude role shift. The former is mainly reflected in the behavior of SELF: within an embedded clause, it can be unbound in the sense of Binding Theory both without and with role shift (9) (c.f., English '*Mom said herself is busy.'), but it cannot appear independently in a matrix clause (14). This contrast indicates that the embedded clause with SELF under attitude role shift ( $9 \mathrm{~b}$, repeated as 15$)$ is not as independent as a pure quotation would be (16). 
Figure 3: Combinations of Attitude Role Shift and SAY with different signing directions

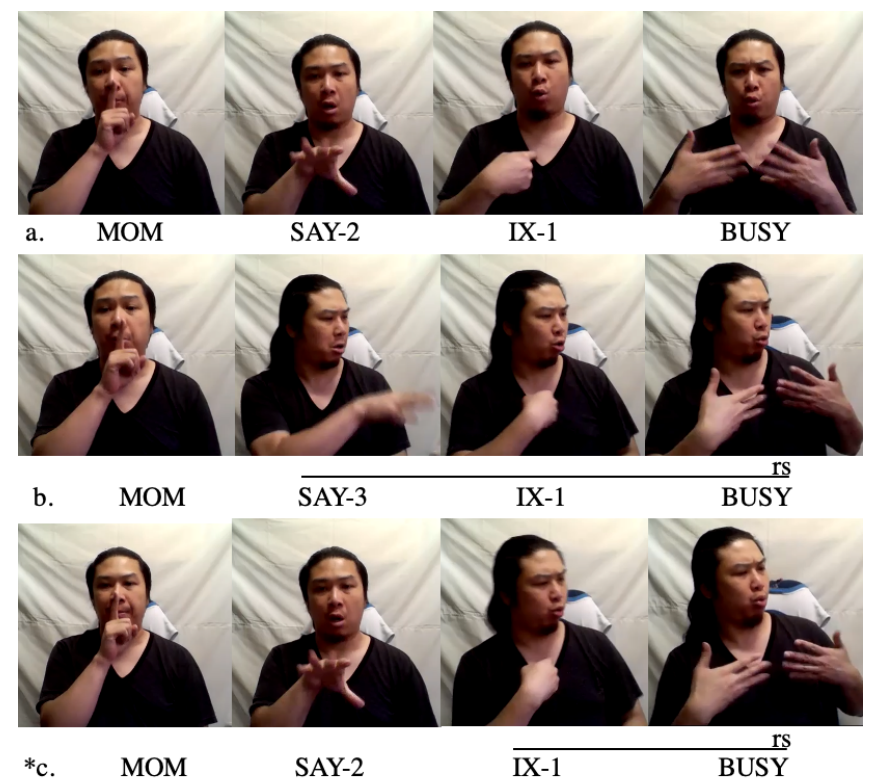

(14) *SELF BUSY Intended:'I am busy.'

(15)

$$
\begin{aligned}
& \operatorname{MOM}_{i} \frac{\text { rs }}{\text { SAY-3 SELF } i / * j \text { BUSY }} \\
& \text { 'Mom said that }\{\text { she is, \#I am\} busy.' }
\end{aligned}
$$

(16) [English]

(a) I am busy.

(b) Mom said: "I am busy!"

On the other hand, some data indicate that attitude role shift in HKSL has quotation-like characteristics. As mentioned above, indexicals under attitude role shift always shift (c.f. indexicals in English quotation (3)), and the extraction of a wh-phrase out of attitude role shift is unacceptable (17). ${ }^{7}$ Note that banning wh-extraction under role shift is not always the case across sign languages. In ASL, for instance, wh-extraction out of role shift is possible (18), which challenges Davidson's Demonstration (quotation) account (Schlenker, 2017a). Nevertheless, it might indicate that role shift in ASL also has some non-quotation-like characteristics, but if so, there are obviously cross-linguistic variations in being quotation-like in some aspects, and non-quotation-like in others.

(17) 'What did the bird playing on the swing feel is problematic?' (CA=constructed action)

(a) IX-3 BIRD $\frac{\text { Ac-rs }}{\text { CA playing-on-the-swing FEEL PROBLEMATIC WHAT }}$

(b) * IX-3 BIRD $\frac{\text { Ac-rs }}{\text { CA playing-on-the-swing FEEL PROBLEMATIC WHAT }}$

(18) WHO WOMAN SAY WHO BUSY WHO

'Who did the woman say was busy?'

[ASL, Koulidobrova and Davidson 2015]

7. The two sentences in this example were adapted and modified from narrative data (CSLDS 2018, SylvesterTweety_ad_CKN), which consists of both action role shift (Ac-rs) and attitude role shift (At-rs) (c.f. similar examples in DGS, Steinbach (2021) and Herrmann and Pendzich (2018)). Nevertheless, it is still clear that in attitude role shift, wh-extraction is not acceptable. 


\section{VERB-2 vS. VERB-3: shift or not?}

Recall that the two signers have different judgements on the sign WE-TWO. Without role shift, for Signer A, the indexical can mean either shifted or non-shifted (10 b), repeated as (19 a), but Signer B only gets the non-shifted interpretation. Interestingly, when the matrix verb changes from SAY-2 to SAY-3, i.e., from straight facing to sideward facing, the ambiguity for Signer A also disappears (19 b). A similar pattern is attested in (20). At first sight, $(20 \mathrm{a})$ seems to show indexical shift, indicating the existence of an indexical shift operator, and the shifting also obeys the Shift Together Constraint (Anand and Nevins 2004). However, when SAY-2 changes to SAY-3 (20 b), the shifted interpretations for the two indexicals are no longer available, challenging this speculation. ${ }^{8}$

(19) (a) CONNIE $i$ SAY-2 WE-TWO $\% i+2 / j+2$ FRIEND

'Connie said that $\{\%$ Connie $\&$ her addressee, signer $\&$ their addressee $\}$ are friends.'(\%: controversial judgements: S.A.: can shift; S.B.: not shift)

(b) CONNIE $_{i}$ SAY-3 WE-TWO $* i+2 / j+2$ FRIEND

'Connie said that $\{\#$ Connie $\&$ her addressee, signer $\&$ their addressee\} are friends.'

(20) Context: Lisa and Connie are having a conversation, Lisa said:

(a) EVA SAY-2 BRENDA IX-1 LIKE IX-2

'Eva told Brenda that \{Eva likes Brenda, Lisa likes Connie\}.'

(b) EVA SAY-3 BRENDA IX-1 LIKE IX-2

'Eva told Brenda that \{\#Eva likes Brenda, Lisa likes Connie\}.'

I propose the shifting of indexicals in (19a) and (20a), but not in (19b) and (20 b) is due to ambiguity caused by the straight signing direction of SAY (marked as SAY-2). Specifically, for agreeing attitude verbs like SAY, the signing direction VERB-2 not only marks a specific second-person agreement with its object, it can also be used as a neutral direction, i.e., not marking the agreement. One piece of evidence is that $(20 \mathrm{a})$ is acceptable with a third person object, BRENDA. ${ }^{9}$ In other words, SAY- 2 can mean 'say to you' or 'say' with the object unspecified on the verb. The ambiguity of VERB-2 leads to two interpretations of the sentence, a plain indirect report or a quotation. As when hearing 'John said I am rich', one can get both interpretations in (21), when seeing the signing of (19a) and (20 a), one can interpret the sentences as a plain indirect report (i.e., indexicals do not shift), or a covert quotation. In other words, the quotation is not overtly marked.

(21) The interpretation for the speech utterance John said I am rich:

(a) John said that I am rich.

(indirect report)

(b) John said: "I am rich."

(covert quotation)

8. A possible way to sustain the claim of an existing indexical shifting operator is to argue that VERB-3 somehow eliminates the operator that is responsible for the shifting.

9. Anecdotal evidence shows that in daily conversation, the same applies to other agreeing verbs that are not attitude verbs. In those cases, VERB-2 indicates an unspecified patient/goal, e.g., AARON GIVE-2 BOOK 'Aaron gives out books.' 
Although attitude role shift in HKSL is not entirely equivalent to quotations in spoken languages, the assumption of a covert quotation leans toward Davidson's account, as the account provides a unified explanation for the shifted indexicals with and without attitude role shift - demonstration. Furthermore, it parallels signed languages with spoken languages. In spoken languages, quotation is not limited to written form but also found in speaking. When speaking, there are various ways to express a quotation (e.g., intonation, a gestural 'air-quote'). In signed languages, similar flexibility also applies. Admittedly, it remains to be explained in more detail how VERB-2 licenses the ambiguity between an indirect report and a covert quotation, and how VERB-3 disambiguates. In addition, we need to find out what causes the cross-signer variations in allowing such an ambiguity.

Based on the data, we can see that indexical shift in HKSL (Table 1) needs to be enriched to consider not only the presence of role shift but also of the exact form of the verb. Moreover, there are at least two levels of interactions among role shift, matrix verbs, and indexical shift: morphological realization and semantic interpretation (Table 2). Specifically, two devices can shift the semantic interpretation of the indexicals: attitude role shift (device 1) and a covert quotation (device 2). ${ }^{10}$ The former is realized by the non-manual marking of role shift, and the latter is introduced by a VERB-2 in an indirect report without any particular non-manual marking. This observation brings up theoretical questions on the nature of role shift, and how it interacts with the matrix verb in the structure.

Table 2: Interactions between role shift (RS), verb direction, and the interpretations

\begin{tabular}{llll} 
RS status & verb direction & clause type interpretation & indexical shift \\
\hline with RS & $*$ VERB -2 & not applicable & not applicable \\
& VERB-3 & attitude RS & obligatory \\
without RS & VERB-2 & covert quotation/indirect report & optional (shifted/no shift) \\
& VERB-3 & indirect report & none \\
\hline
\end{tabular}

\section{Notes On TOMORROW \& SELF}

Before concluding, let me discuss two signs briefly:

TOMORROw. With and without role shift, the sign TOMORROW necessarily shifts to the reported context. I propose that this is caused by a purely lexical reason. Specifically, TO-

10. Vadim Kimmelman (p.c.) and Diane Lillo-Martion (p.c.) both point out that the ambiguity caused by VERB-2 could be one between an indirect report without role shift (indexicals do not shift), and one with a covert role shift (indexicals always shift). There are two main reasons why I stick to the idea of a 'covert quotation' instead of a 'covert role shift'. First, claiming a 'covert role shift' brings up several technical puzzles. For instance, although indexicals under role shift necessarily shift in HKSL, it is not the case in all sign languages, e.g. RSL. This proposal will require further stipulations to account for cross-linguistic variations. On the other hand, adopting 'quotation' can account for the HKSL data in which indexicals shift without role shift, while still agreeing with the common findings on quotations cross-linguistically. Second, claiming a covert and overt realization of role shift implies that it is an abstract category common in human languages. However, role shift is a form of linguistic expression specific to sign languages. If it is a category, one would need to explain why spoken languages do not adopt role shift in the same way as sign languages. Of course, one could argue that role shift is a sign-language-specific instantiation of a more general abstract category, in a similar spirit to Schlenker's proposal that role shift is an indexical shifting operator. But then this goes back to the original puzzle on the nature of role shift, which I claim that neither the Demonstration Account nor the Indexical Shifting Operator Account suffices to fully answer. 
MORROW appears to be a lexical item that bares the meaning of 'the next day', instead of an indexical that can shift according to the context. One piece of (indirect) evidence is that in narratives, TOMORROW refers to 'the next day' regardless of the past tense of the discourse, as in (22). Admittedly, more tests are required to confirm this speculation.

(22) TOMORROW MORNING, IX $a$ FROG ABSENT

'The next morning, the frog disappeared.'

(CSLDS 2018, Frog_ad_WK:00:00:54)

SELF. The data also reveal that the sign SELF is, with regards to Condition A of the Binding Theory, different from reflexives in English, in that SELF can be unbound in an indirect sentence (9 a). However, its non-independence in a matrix clause (14) indicates that it can only appear in the subject position of an embedded sentence, not a matrix one. One possibility is that SELF has various uses, similar to ziji in Mandarin Chinese (Huang, Li, and Li 2009; Charnavel 2019, a.o.). As in (23 a), ziji can be bound by Lisi, indicating that it is an anaphor and not a pronoun, but it can also be bound by a long-distance antecedent Zhangsan, which has a logophor interpretation. In addition, the combination of a pronoun and ziji behaves like a regular reflexive ( $23 \mathrm{~b}$ ), which obeys Binding Condition A; Moreover, ziji can also act as an emphatic reflexive, expressing 'by oneself' (23 c).

(23) [Chinese, (a) \& (b) adopted from Huang, Li, and Li 2009, p.330-331]

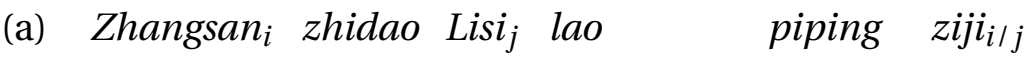
zhangsan know Lisi incessantly criticize self

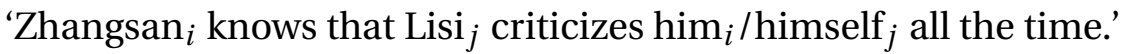

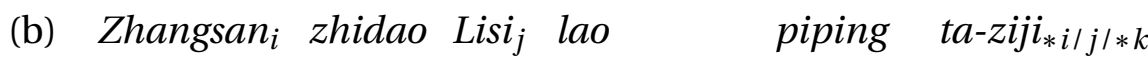
zhangsan know Lisi incessantly criticize 3SG-self

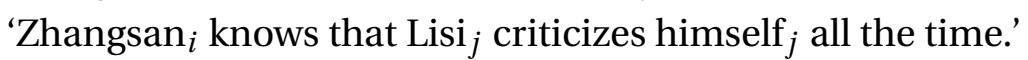
(c) Ta ziji xie wan le zuoye
3SG self write finish PERF homework
'S/He finished her/his homework by herself/himself.'

Assuming SELF in HKSL is similarly polysemous, it could be the case that SELF can act as a logophor, which explains its unboundedness in (9a) and the non-independence in a matrix clause in (14). Moreover, it can also be used as an emphatic reflexive, meaning 'by oneself', as in (24). Recall that SELF also appears unbounded in a clause under attitude role shift (15), leading to the interim conclusion that the clause under attitude role shift has an intermediate status between a quoted clause in the quotation (i.e., an independent clause) and a (non-independent) embedded clause (as discussed in Section 5, (15) vs. (14)). Thus, understanding the behavior of SELF in HKSL is crucial for understanding the nature of attitude role shift. Due to time and space, I leave an in-depth discussion for future research.

\footnotetext{
IX-1 SELF SHOPPING

'I went shopping by myself.'
}

\section{Concluding remarks}

In this paper, I discuss shifted indexicals in HKSL. The data show that in HKSL, indexical shifting is not limited to sentences with non-manual marking of role shift. Moreover, attitude role shift reveals both quotation-like and non-quotation-like characteristics. Thus, neither Davidson's (2015) Demonstration (quotation) Account nor Schlenker's (2017a, 2017b) 
Indexical Shifting Operator Account suffices to fully account for role shift. Further evidence shows that the morphological form of the matrix verb affects the interpretation of the embedded clause without role shift, and consequently the shifting of the indexicals. I propose that the straight facing signing direction (VERB-2) causes an ambiguity in interpreting the sentence as an indirect report (the embedded indexicals do not shift) or a covert quotation (the indexicals shift to the reported context).

Several questions remain to be solved: How does role shift interact with the sign SELF? What causes cross-signer variations in the judgement on TODAY and in allowing the ambiguity brought by VERB-2? How does the morphological form of the matrix attitude verbs relate to agreement marking (i.e., the syntactic complement of the verbs) and how does it interact with role shift in general? Further scrutiny is needed to understand the semantic and syntactic nature of role shift.

\section{Acknowledgments}

I sincerely thank my Deaf consultants in Hong Kong SAR (Aaron Wong, Kenny Chu), my advisors (Diane Lillo-Martin, Magdalena Kaufmann), the audiences at Uconn Sign Language Research and Discussion Group (SLRDG) and FEAST 2021 Conference who raised valuable questions and comments, anonymous reviewers, and the editors. All errors are mine.

\section{References}

Anand, Pranav, and Andrew Nevins. 2004. "Shifty operators in changing contexts." In Proceedings of SALT 14. Ithaca, NY: CLC Publication.

Charnavel, Isabelle. 2019. Locality and Logophoricity-A Theory of Exempt Anaphora. Oxford University Press.

Cormier, Kearsy, Sandra Smith, and Zed Sevcikova-Sehyr. 2015. "Rethinking constructed action.” Sign Language \& Linguistics 18 (2): 167-204. https: / / doi.org / 10.1075 / sll.18.2. 01cor.

Cormier, Kearsy, Stephen Wechsler, and Richard Meier. 1998. "Locus agreement in American Sign Language." In Lexical and Constructional Aspects of Linguistic Explanation, edited by Gert Webelhuth, Jean-Pierre Koenig, and Andreas Kathol, 215-229. Stanford, CA: CSLI.

CSLDS. 2018. “Hong Kong Sign Language Corpus.” Corpus. http://www.cslds.org/hkslcorpu s/.

Davidson, Kathryn. 2015. "Quotation, demonstration, and iconicity." Linguistics and Philosophy 38 (6): 477-520. https://doi.org/10.1007/s10988-015-9180-1.

Deal, Amy Rose. 2020. A Theory of Indexical Shift-Meaning, Grammar, and Crosslinguistic Variation. Cambridge, MA; London, England: The MIT Press.

Herrmann, Annika, and Nina-Kristin Pendzich. 2018. "Between narrator and protagonist in fables of German Sign Language.” In Linguistic Foundations of Narration in Spoken and Sign Languages, edited by Annika Hübl and Markus Steinbach, 275-308. John Benjamins Publishing Company. 
Herrmann, Annika, and Markus Steinbach. 2012. "Quotation in sign languages: a visible context shift." In Quotatives: Cross-linguistic and Cross-Disciplinary Perspectives, edited by Isabelle Buchstaller and Ingrid van Alphen, 203-228. Amsterdam: John Benjamins Publishing Company. https://doi.org/10.1075/celcr.15.12her.

Huang, Cheng-Teh James., Yen-hui Audrey Li, and Yafei Li. 2009. The Syntax of Chinese. New York: Cambridge University Press.

Hübl, Annika. 2012. "Role shift, indexicals and beyond - new evidence from German Sign Language.” In Proceedings from the 13th meeting of the Texas Linguistics Society, 1-11.

Hübl, Annika, Emar Maier, and Markus Steinbach. 2019. "To shift or not to shift: Indexical attraction in role shift in German Sign Language.” Sign Language \& Linguistics 22 (2): 171-209. https://doi.org/10.1075/sll.18004.hub.

Kaplan, David. 1989. "Demonstratives: an essay on the semantics, logic, metaphysics and epistemology of demonstratives and other indexicals." In Themes from Kaplan, edited by Joseph Almog, John Perry, and Howard Wettstein, 481-563. Oxford University Press.

Kimmelman, Vadim, and Evgeniia Khristoforova. 2018. "Quotation in Russian Sign Language: insights from corpus and elicitation." FEAST. Formal and Experimental Advances in Sign language Theory 2:93-102. ISSN: 2565-1781, accessed April 12, 2021. https://doi.org/10. 31009/FEAST.i2.08. https:/ / www.raco.cat/index.php/FEAST/article/view/10.31009FEAST.i2.08.

Koulidobrova, Elena, and Kathryn Davidson. 2015. "Watch the attitude: embedding and roleshift in ASL.” In Proceedings of Sinn und Bedeutung, 19:358-376. https: / / doi .org/ 10. 18148/sub/2015.v19i0.238.

. 2020. "Attitude embedding predicates and indexicals under role shift in ASL." In Making Worlds Accessible. Essays in Honor of Angelika Kratzer, edited by Rajesh Bhatt, Ilaria Frana, and Paula MenÃ, 59-71.

Lillo-Martin, Diane. 2012. “Utterance reports and constructed action.” In Sign language: An international handbook, edited by Roland Pfau, Markus Steinbach, and Bencie Woll, 365-387. Berlin: Mouton de Gruyter.

Padden, Carol A. 1988. "Interaction of Morphology and Syntax in American Sign Language." PhD diss., University of California, San Diego.

Park, Yangsook. 2014. "Indexicals and the long-distance reflexive caki in Korean." In Proceedings from SALT XIV. CLS Publications.

Quer, Josep. 2011. "Reporting and quoting in signed discourse." In Understanding Quotation, edited by Elke Brendel, Jörg Meibauer, and Markus Steinbach. Berlin, New York: De Gruyter Mouton. https://doi.org/10.1515/9783110240085.277.

2013. "Attitude ascriptions in sign languages and role shift." In Texas Linguistics Forum: Proceedings from the 13th meeting of the Texas Linguistics Society, 12-28. The 13th Meeting of the Texas Linguistics Society.

. 2016. "Reporting with and without role shift: sign language strategies of complementation." In A Matter of Complexity, edited by Roland Pfau, Markus Steinbach, and Annika Herrmann, 204-230. De Gruyter Mouton. https://doi.org/10.1515/9781501503238-009. 
Schlenker, Philippe. 2003. “A plea for monsters.” Linguistics and Philosophy 26 (1): 29-120.

- 2011. "Indexicality and De Se reports." In Semantics-An International Handbook of Natural Language Meaning (Volume 2), edited by Klaus von Heusinger, Claudia Maienborn, and Paul Portner, 1561-1604. Berlin/Boston: De Gruyter Mouton.

_. 2017a. "Super monsters I: attitude and action role shift in sign language." Semantics and Pragmatics 10 (9). https:// doi.org/10.3765/sp.10.9.

2017b. "Super monsters II: Role Shift, iconicity and quotation in sign language." Semantics and Pragmatics 10 (9). https://doi.org/10.3765/sp.10.12.

Steinbach, Markus. 2021. "Role shift." In The Routledge Handbook of Theoretical and Experimental Sign Language Research, edited by Josep Quer, Roland Pfau, and Annika Herrmann, 351-377. London: Routledge. https://doi.org/10.4324/9781315754499.

Supalla, Ted. 1986. “The classifier system in American sign language.” In Noun Classes and Categorization: Proceedings of a Symposium on Categorization and Noun Classification, edited by Colette Grinevald Craig, 181-214. Eugene, Oregon: John Benjamins Publishing.

Zucchi, Sandro. 2004. "Monsters in the visual mode?" Ms., Milan, Università degli Studi di Milano, Università degli Studi di Milano. http://www.filosofia.unimi.it/ zucchi/Nuovi File/LISmonsters.pdf. 